\title{
Nutritional Aspect of Methionine Isomers Studied by Pulmonary Exhalation of Dimethyl Sulfide and Urinary Excretion of $\alpha$-Keto- $\gamma$-methiolbutyrate in Humans
}

\author{
Hiroshi Kaji, MD, Nariyoshi Saito*, MD, Masaya Hisamura*, MD, \\ Makoto Murao**, MD, Makoto Ishimoto***, PhD, \\ Hiroyuki Kondo***, $\mathrm{PhD}$ and Kazuo SaIto, MD
}

\begin{abstract}
With the view of evaluating the relative utilization of methionine isomers, the pulmonary exhalation of dimethyl sulfide and methyl mercaptan and the urinary excretion of $\alpha$-keto- $\gamma$-methiolbutyrate were studied in normal healthy subjects following oral or intravenous administration of L- or D-isomer of methionine. Dimethyl sulfide concentration in the expired alveolar gas (mean \pm SD) before methionine loading was $2.1 \pm 1.4 \mathrm{ng} / \mathrm{dl}(\mathrm{N}=23)$. Maximum concentrations of dimethyl sulfide in oral methionine loading tests were: $56.0 \pm 24.9 \mathrm{ng} / \mathrm{dl}(\mathrm{D}-2 \mathrm{~g})(\mathrm{n}=4), 66.0 \pm 42.1(\mathrm{D}-1 \mathrm{~g})(\mathrm{N}=6)$ and $4.6 \pm 2.6(\mathrm{~L}-2 \mathrm{~g})(\mathrm{N}=4)$; and in intravenous loading tests: $60.0 \pm 19.9(\mathrm{D}-1 \mathrm{~g})(\mathrm{N}=4)$ and $4.2 \pm 2.1(\mathrm{~L}-2 \mathrm{~g})(\mathrm{N}=3)$, respectively. The changes in methyl mercaptan in the expired alveolar gas were small and were disproportional to the changes in dimethyl sulfide following administration of both isomers. Preloading concentration of $\alpha$-keto$\gamma$-methiolbutyrate in urine was $0.15 \pm 0.10 \mu \mathrm{g} / \mathrm{mg}$ Creatinine (mean $\pm \mathrm{SD}$ ) $(\mathrm{N}=5)$. Postloading values during the initial two hours were 578 and $156 \mu \mathrm{g} / \mathrm{mg}$ Creatinine following $3 \mathrm{~g}$ of D- and 0.20 and $29.7 \mu \mathrm{g} / \mathrm{mg}$ Creatinine following $3 \mathrm{~g}$ of $\mathrm{L}$-methionine ingestion. In view of the results obtained, significant amounts of D-methionine seem to be metabolized through the transaminative pathway of methionine metabolism.
\end{abstract}

Key Words: . Methyl mercaptan, Expired alveolar gas, Breath analysis, Gas chromatography, Methionine loading test

\section{INTRODUCTION}

DL-Methionine has long been used for the treatment of hepatic disorders ${ }^{1}$. Such a treatment was established on the basis that L-methionine is an essential amino acid for man and unnatural Disomer is utilized after oxidative deamination to its $\alpha$-keto analogue and subsequent reamination to L-isomer ${ }^{2-4)}$. Nevertheless, poor utilization of Disomer of methionine has recently been pointed out in young infants and in postoperative patients receiving the total parenteral nutrition containing L- or D-methionine ${ }^{5-7)}$. At this point of time, the utilization of methionine isomers should be re- evaluated from the metabolic and the nutritional stand point of view. The authors have been engaged in the breath analysis for volatile sulfur compounds, such as methyl mercaptan, ethyl mercaptan, dimethyl sulfide and dimethyl disulfide, and have reported the remarkable difference in dimethyl sulfide exhalation following ingestion of methionine isomers ${ }^{8)}$. In this report, summary of the quantitative determination of breath dimethyl sulfide following administration of $\mathrm{D}$ - or Lmethionine was presented and the metabolic difference between D- and L-isomer was discussed together with the preliminary data on the urinary excretion of $\alpha$-keto- $\gamma$-methiolbutyrate.

From Department of Environmental Medicine, Graduate School of Environmental Science,

Hokkaido University, Kita-10, Nishi-5, Kita-ku, Sapporo, 060.

*The First Department of Internal Medicine, Hokkaido University School of Medicine, Sapporo.

**The Second Department of Internal Medicine, School of Medicine, Teikyo University, Tokyo.

***Department of Chemical Microbiology, Faculty of Pharmaceutical Sciences, Hokkaido University.

Received for publication October 22, 1982.

Reprint request to: Hiroshi Kaji, MD, Department of Environmental Medicine, Graduate School of Environmental Science, Hokkaido University, Kita-10, Nishi-5, Kita-ku, Sapporo, 060, Japan. 


\section{MATERIALS AND METHODS}

Chemicals: Standard benzene solutions of dimethyl sulfide (abb. DMS) $(0.1 \mu \mathrm{g} / \mu \mathrm{l})$. and methyl mercaptan (abb. MM) (1 $\mu \mathrm{g} / \mu \mathrm{l})$ were obtained from Wako Pure Chemical Industries, Ltd., Osaka. $\alpha$-Keto- $\gamma$-methiolbutyrate (abb. AKMTB) was obtained from SIGMA Chemical Company, Inc., St. Louis, MO, U.S.A. Methionines used in the present investigation were as follows: special grade L- and D-methionine (Wako Pure Chemical Industries, Ltd., Osaka), and L-methionine solution for medical use (Takeda Chemical Industries, Ltd., Osaka). D-Methionine solution for intravenous injection was prepared in the Pharmaceutics Section of the Hokkaido University Hospital $^{9)}$.

Analysis of expired alveolar gas for dimethyl sulfide and methyl mercaptan: A gas chromatograph equipped with a flame photometric detector and with a hydrogen flame ionization detector monitor (Model GG-5AP $\mathrm{AFF}_{\mathrm{p}}$, Shimadzu) was used for the anlysis of expired alveolar gas. Routinely, $100 \mathrm{ml}$ of expired alveolar gas sample were collected at the pharyngeal portion with the syringe of $100-\mathrm{ml}$ capacity nearly at the end of a prolonged uninterrupted expiration after 20second breathholding. Details of analytical procedures have been described elsewhere ${ }^{10,11)}$.

Analysis of urine for $\alpha$-keto- $\gamma$-methiolbutyrate (abb. AKMTB): Five $\mathrm{ml}$ of standard AKMTB solution or 5 to $25 \mathrm{ml}$ of urine samples were acidified by hydrochloric acid to $\mathrm{pH} 1.0$ and extracted five times with diethyl ether. The pooled ether phase was concentrated to $5 \mathrm{ml}$ under vacuum and further extracted three times with a $5 \%$ aqueous solution of $\mathrm{NaHCO}_{3}$. The water phase was re-acidified by hydrochloric acid to $\mathrm{pH} 1.0$, and AKMTB was converted to the quinoxalinol derivative with o-phenylenediamine hydrochloride using the method of Favier and Caillat ${ }^{12)}$. The quinoxalinol derivative was quantitatively analyzed by a gas chromatograph equipped with a flame photometric detector (GC-6APF $p$, Shima$\mathrm{dzu})^{13)}$.

Methionine loading tests in normal volunteers: Twenty experimental subjects $(17$ males and 3 females, aged from 18 to 42 years) were tested for the total 28 times. Extremely obese or lean sub- jects were not included. These subjects were divided into three groups for methionine loading tests. The first was the oral methionine loading test for the expired alveolar gas analysis. After overnight-fasting, fourteen subjects were given 2 or $1 \mathrm{~g}$ of L- or D-methionine orally with $200 \mathrm{ml}$ of tapid water regardless of body weight. The concentrations of dimethyl sulfide and methyl mercaptan in expired alveolar gas (abb. alv-DMS and alv-MM) were determined at 30 - or 60 -minutes intervals for 4 hours. The second was the intravenous methionine loading test for the expired alveolar gas analysis. With reference to the oral methionine loading test, nine subjects were administered $2 \mathrm{~g}$ of $\mathrm{L}$ - and 0.5 or $1 \mathrm{~g}$ of D-methionine and expired alveolar gas samples were analyzed for alv-DMS in the same way. The third was the oral methionine loading test for the urinary AKMTB analysis. After overnight-fasting, three healthy subjects (one male and two females) ingested $3 \mathrm{~g}$ of $\mathrm{L}$ - or $3 \mathrm{~g}$ (or $1 \mathrm{~g}$ ) of D-methionine and urine samples were collected hourly for 4 hours. In subject B, expired alveolar gas was also analyzed for alv-DMS and alv-MM.

Student's t-test was used in the statistical analysis.

\section{RESULTS}

Exp. 1. Determination of alv-DMS in oral methionine loading test: Fasting level of alvDMS was $2.3 \pm 1.4 \mathrm{ng} / \mathrm{dl}$ (mean $\pm \mathrm{SD})(\mathrm{N}=14)$ (Table 1). Following ingestion of $2 \mathrm{~g}$ or $1 \mathrm{~g}$ of $\mathrm{D}$ methionine, alv-DMS increased distinctly in 30 to 90 minutes and then decreased gradually till the end of the observation period; postloading maximum concentrations of alv-DMS were 56.0 $\pm 24.9 \mathrm{ng} / \mathrm{dl}$ (2g loading) and $66.0 \pm 42.1 \mathrm{ng} / \mathrm{dl}$ (1g loading). Following ingestion of $2 \mathrm{~g}$ of $\mathrm{L}$ methionine, however, alv-DMS showed a little increase; postloading maximum value was $4.6 \pm$ $2.6 \mathrm{ng} / \mathrm{dl}$. Alv-MM was also determined following $1 \mathrm{~g}$ of D-methionine ingestion. The behavior of alv-MM was different from that of alv-DMS (Fig. 1 Center and Fig. 2).

Exp. 2. Determination of alv-DMS in intravenous methionine loading test: Fasting level of alv-DMS was $1.9 \pm 1.3 \mathrm{ng} / \mathrm{dl}($ mean $\pm \mathrm{SD})(\mathrm{N}=9)$ (Table 2). Following intravenous injection of $1 \mathrm{~g}$ 
Table 1. Oral methionine loading test for dimethyl sulfide in expired alveolar gas (alv-DMS)

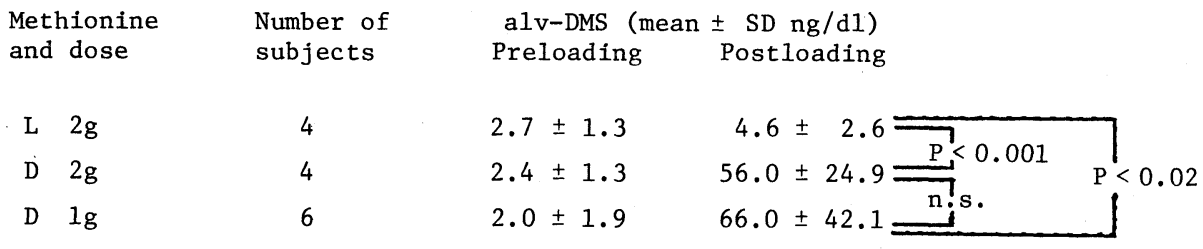

Table 2. Intravenous methionine loading test for dimethyl sulfide in expired alveolar gas (alvDMS)

$\begin{array}{llrl}\text { Methionine } & \text { Number of } & \text { alv-DMS (mean } \pm \text { SD ng/dl) } \\ \text { and dose } & \text { subjects } & \text { Preloading } & \text { Postloading }\end{array}$
L $\quad 2 \mathrm{~g}$
$3.0 \pm 1.4$
D $\quad 1 \mathrm{~g}$
$1.4 \pm 0.9$
D $0.5 \mathrm{~g}$
4
$1.0 \pm 0.4$

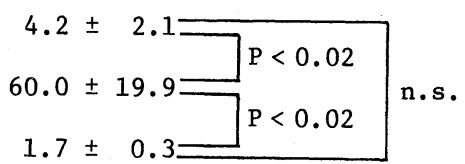

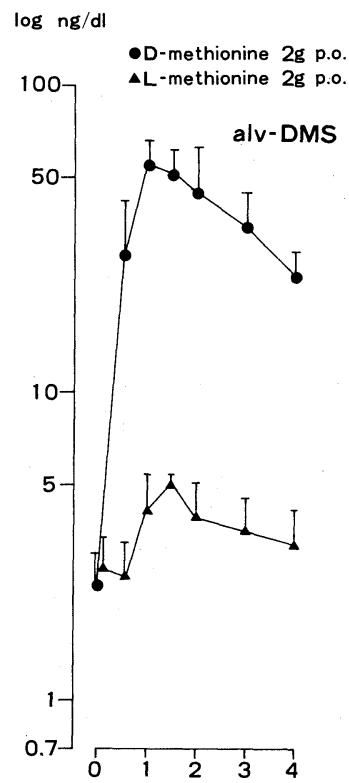

D-methionine $1 \mathrm{~g}$ i.v. -D-methionine $0.5 \mathrm{~g}$ i.v. $\triangle \mathrm{L}$-methionine $2 \mathrm{~g}$ i.v.

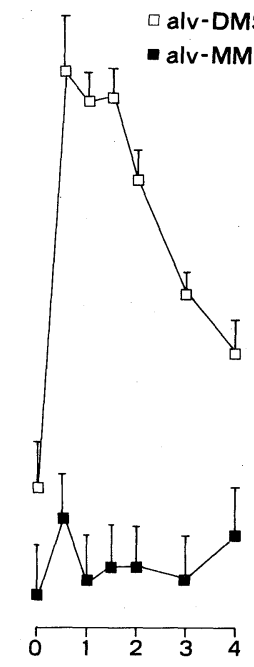
alv-DMS

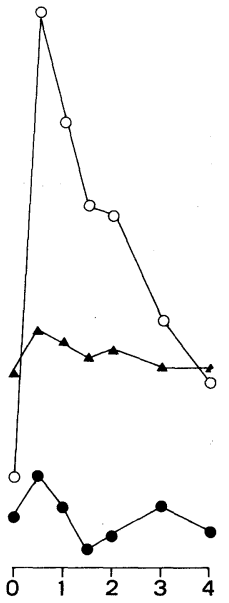

TIME HOURS

Fig. 1. Oral and intravenous methionine loading tests for dimethyl sulfide and methyl mercaptan in expired alveolar gas (alv-DMS and alv$\mathrm{MM})$ (mean $\pm \mathrm{SE} \mathrm{ng} / \mathrm{dl}$ ). Left: Changes in alv-DMS following ingestion of $2 \mathrm{~g}$ of $\mathrm{D}$ - and L-methionine ( $\mathrm{D}-\mathrm{N} \mathrm{N}=4 ; \mathrm{L}-\mathrm{N}=4)$ ). Center: Ingestion of $1 \mathrm{~g}$ of $\mathrm{D}$-methionine $(\mathrm{N}=6)$. Right: Intravenous methionine loading tests (mean, $\mathrm{ng} / \mathrm{dl}) ; 2 \mathrm{~g}$ of $\mathrm{L}-(\mathrm{N}=3), 1 \mathrm{~g}$ of $\mathrm{D}-(\mathrm{N}=4)$ and $0.5 \mathrm{~g}$ of D-methionine $(\mathrm{N}=2)$, respectively. 
of D-methionine, alv-DMS increased rapidly to the peak value of $60.0 \pm 19.9 \mathrm{ng} / \mathrm{dl}$ within 30 minutes, but $2 \mathrm{~g}$ of L-methionine infusion caused quite a little or no increase; postloading maximum value was $4.2 \pm 2.1 \mathrm{ng} / \mathrm{dl}$ (Fig. $1 \mathrm{Right}$ ) (Table 2). Intravenous injection of $500 \mathrm{mg}$ of D-methionine did not cause apparent increase in alv-DMS.

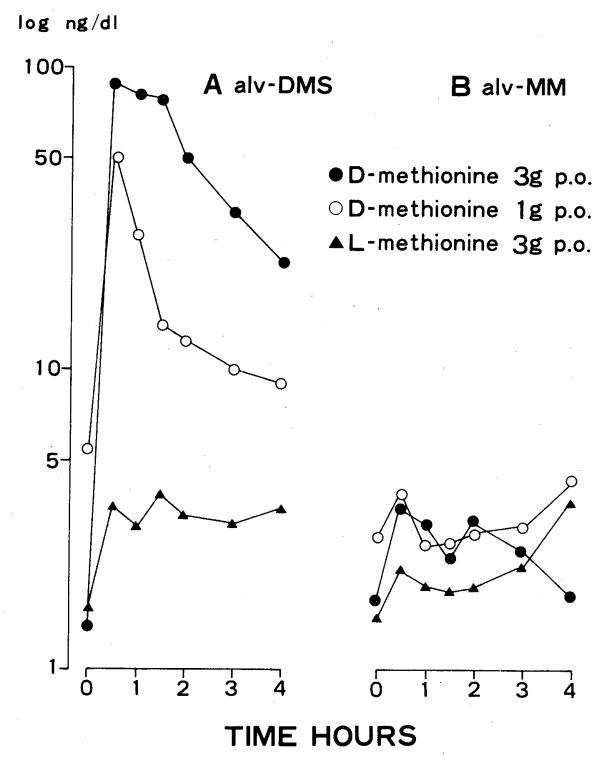

Fig. 2. Oral methionine loading tests for dimethyl sulfide and methyl mercaptan in expired alveolar gas (alv-DMS and alv-MM) following ingestion of $3 \mathrm{~g}$ of $\mathrm{D}$-, $1 \mathrm{~g}$ of $\mathrm{D}$ - and $3 \mathrm{~g}$ of L-methionine studied in a 42-yearold male.
Exp. 3. Preliminary experiment for the determination of urinary excretion of AKMTB in oral methionine loading test: In order to probe the dosage of methionine isomers to get the detectable urinary concentration of AKMTB, the total 4 times of $3 \mathrm{~g}$-loading test was performed in 3 healthy subjects, and in subject B, 1g-D-methionine loading test was also performed. Urine samples were pooled as follows; pooled urine A was the mixture of urines of 1 st and 2 nd hour period and pooled urine $B$ was that of 3rd and 4th hour period. Urinary AKMTB concentration was converted into $\mu \mathrm{g}$ per $\mathrm{mg}$ of creatinine ( $\mu \mathrm{g} / \mathrm{mg}$ Creat.) (Table 3). Preloading concentration was $0.15 \pm$ $0.10 \mu \mathrm{g} / \mathrm{mg}$ Creat. (mean $\pm \mathrm{SD}$ ) considering all the experimental subject $(\mathrm{N}=5)$. When $3 \mathrm{~g}$ of $\mathrm{D}$ methionine were administered, urinary AKMTB increased distinctly and this tendency was also observed following administration of $1 \mathrm{~g}$ of $\mathrm{D}$ methionine. When $3 \mathrm{~g}$ of $\mathrm{L}$-methionine were administered, however, its increase was apparently small. In subject-B, alv-DMS and alv-MM were also determined serially and were compared with the urinary excretion of AKMTB. Again, the behavior of alv-MM was different from that of alv-DMS (Fig. 2). Knowing full well that the concentration of volatile substances in the expired alveolar gas is higher than that in the tidal air, the pulmonary exhalation of DMS and MM were roughly calculated by measuring the minute

Table 3. Oral methionine loading test for $\alpha$-keto- $\gamma$-methiolbutyrate (AKMTB) in urine

Urinary AKMTB ( $\mu \mathrm{g} / \mathrm{mgCreat.)}$

\begin{tabular}{cccccccc}
\multicolumn{2}{l}{$\begin{array}{l}\text { Experimental subjects } \\
\text { Subject }\end{array}$} & Sex and age & \multicolumn{2}{l}{$\begin{array}{l}\text { Methionine } \\
\text { and dose }\end{array}$} & $\begin{array}{l}\text { Before } \\
\text { ingestion }\end{array}$ & Urine A* & Urine B* \\
A & female & 36 & D & $3 g$ & 0.11 & 578 & 767 \\
B & male & 42 & D & $3 g$ & 0.05 & 156 & 81.5 \\
B & male & 42 & D & $1 \mathrm{~g}$ & 0.29 & 272 & 63.5 \\
B & male & 42 & L & $3 g$ & 0.21 & 0.20 & 0.43 \\
C female & 36 & L & $3 g$ & 0.09 & 29.7 & 58.5 \\
A*: pooled urine of 1st and 2nd hour & & & \\
B*: pooled urine of 3rd and 4th hour &
\end{tabular}


Table 4. The amount ( $\mu$ moles) of pulmonary exhalation of dimethyl sulfide and methyl mercaptan (alv-DMS, alv-MM) and urinary excretion of $\alpha$-keto- $\gamma$-methiolbutyrate (AKMTB) following ingestion of $3 \mathrm{~g}$ of $\mathrm{D}$-methionine in 42-year-old man.

D-methionine loading test

$\begin{array}{lcccc}\begin{array}{l}\text { Substances } \\ \text { analyzed }\end{array} & \begin{array}{l}2 \text { hours before } \\ \text { examination }\end{array} & \begin{array}{c}\text { initial } \\ 2 \text { hours }\end{array} & \begin{array}{c}\text { next } \\ 2 \text { hours }\end{array} & \begin{array}{c}\text { total in } \\ 4 \text { hours }\end{array} \\ \text { alv-DMS } & 0.22 & 10.7 & 5.4 & 16.1 \\ \text { alv-MM } & 0.34 & 0.58 & 0.50 & 1.08 \\ \text { AKMTB } & 0.07 & 151.9 & 70.6 & 222.5\end{array}$

respiratory volume $(8.06 \mathrm{~L} / \mathrm{min})$ and were compared with the amounts of AKMTB excreted in urine (Table 4). It was indicated that, in subject $\mathrm{B}$, at least $1.2 \%$ of $\mathrm{D}$-methionine was excreted in breath and urine as DMS, MM and AKMTB in 4 hours after ingestion of 20 mmoles of D-methionine.

\section{DISCUSSION}

In the present investigation, it was demonstrated that alv-DMS increased distinctly following both oral and intravenous administration of D-methionine and its peak moved from 60 minutes after oral to 30 minutes after intravenous administration. This divergence of time seems to reflect the factors of gastrointestinal transition and intestinal absorption ${ }^{14}$ ). In contrast, alv-DMS did not show such an apparent increase following administration of L-methionine (Fig. 1) (Table 1, $2)$. In the same way, urinary excretion of AKMTB increased markedly following D-methionine and its increase was small in the case of L-methionine ingestion (Table 3). In effect, a distinct increase in alv-DMS following D-methionine administration seems to be related to the increase in urinary excretion of AKMTB. It is an important observation that the changes in alv-MM are disproportionally small and are different from the changes in alvDMS. These results suggest that significant amounts of D-methionine may be converted into AKMTB and that DMS may be formed from Dmethionine via AKMTB.

L-Methionine is an essential amino acid for man and unnatural $\mathrm{D}$-methionine is believed to be utilized after oxidative deamination to $\alpha$-keto analogue and subsequent reamination to L-isomer in a reaction of transamination ${ }^{2-4)}$. Recently, the transaminative pathway of methionine catabolism has been demonstrated in vitro using rat and monkey liver homogenate, independent of Sadenosylmethionine formation. This pathway has been postulated to involve conversion of $\mathrm{L}$ methionine to AKMTB which then is oxidatively decarboxylated to 3-methylthiopropionate, furthermore, methyl mercaptan, hydrogen sulfide, sulfate, formaldehyde, formate and carbon dioxide are produced as the metabolic products of 3methylthiopropionate in rat liver homogenate system ${ }^{15-17)}$. If one assumes that AKMTB can be efficiently converted into L-methionine, distinct increase in alv-DMS should not have been observed in our experimental system since alv-DMS did not increase following administration of L-methionine. Less alv-DMS exhalation seems to indicate better utilization of mehionine. As stated above, 3methylthiopropionate is produced via AKMTB when massive doses of L-methionine are administered $^{15,16)}$. If 3 -methylthiopropionate were further methylated to dimethyl $\beta$-propiothetin, however, it may be tentatively assumed that the latter compound might be metabolized to dimethyl sulfide as one of the product of the transaminative pathway of methionine metabolizm. Also, theoretically, dimethyl sulfide may be formed from $\alpha$-keto- $\gamma$-methiolbutyrate- $\delta$-dimethyl sulfonium produced by the methylation of AKMTB.

Methyl mercaptan has been stated to arise from methionine by hydrolytic or reductive fission giving homoserine or $\alpha$-aminobutyrate ${ }^{i \delta-20)}$, and it has also been reported to be formed trom 
AKMTB more rapidly than from methionine itself $^{21)}$. Since methyl mercaptan is generally believed to be readily oxidized to dimethyl disulfide $^{20,22)}$, it is possible that, when methyl mercaptan is produced, a buildup of dimethyl sulfide by methylation may occur very soon in body fluid or tissues. Despite the marked increase in alv-DMS after D-methionine administration, alv-MM did not always increase and it did not behave parallel to alv-DMS and urinary AKMTB (Fig. 1 Center and Fig. 2) (Table 4). Therefore, even if small portion of dimethyl sulfide was formed from methyl mercaptan, it can probably be assumed that most of dimethyl sulfide was formed by the mechanisms described above. It has been also demonstrasted in the study of human and primate that 10 to $70 \%$ of orally or parenterally administered D-methionine are excreted promptly in urine and that the rate of disappearance for D-methionine from circulating blood is higher than that for L-methionine ${ }^{5-7)}$.

In view of these results, it seems to be likely that significant amounts of D-methionine are converted to AKMTB, that distinct increase in exhalation of dimethyl sulfide is closely related to the marked increase in urinary excretion of AKMTB, and that the utilization of D-isomer is poorer than that of L-isomer. D-Methionine metabolism should be further studied in relation to the hepatic transsulfuration mechanism in company with the renal and/or the hepatic Damino acid oxidase ${ }^{4,20)}$.

\section{REFERENCES}

1) Practice in Clinical Medication, 2nd ed, part 2. Agents used for liver dysfunction. (Abe H, Mashimo K, Sambe K, Ozawa K, eds), Daiichi Seiyaku Co., Ltd., Tokyo, p 405, 1978.

2) Biochemistry of the Amino Acids. (Meister A, ed), Academic Press, New York. London, 1965.

3) Harper AE, Benevenga NJ \& Wohlhueter RM: Effects of ingestion of disproportionate amounts of amino acids. Physiol. Rev. 50: 428, 1970.

4) Review of Physiological Chemistry. (Harper HA, ed), Lange Medical Publications, Los Altos, California, 1967.

5) Stegink LD, Schmitt JL, Meyer PD, et al: Effect of diets fortified with DL-methionine on urinary and plasma methionine levels in young infants. J. Pediatrics 79: 648, 1971.

6) Printen $\mathrm{KJ}$, Brummel MC, Cho ES, et al: Utilization of D-methionine during total parenteral nutrition in postsurgical patients. Am. J. Clin. Nutr. 32: 1200, 1979.

7) Stegink LD, Moss J, Printen KJ, et al: D-Methionine utilization in adult monkeys fed diets containing DLmethionine. J. Nutr. 110: 1240, 1980.

8) Kaji H, Hisamura M, Saito N, et al: Clinical application of breath analysis for dimethyl sulfide following ingestion of DL-methionine. Clin. Chim. Acta 93: 377, 1979.

9) Japan Pharmacopoeia, 8th ed, Hirokawa Shoten, Tokyo, p C1650-C1661, 1971.

10) Kaji H, Hisamura M, Saito N, et al: Gas chromatographic determination of volatile sulfur compounds in the expired alveolar air in hepatopathic subjects. J. Chromatogr. 145: 464, 1978.

11) Kaji H, Hisamura $M$, Saito $N$, et al: Evaluation of volatile sulfur compounds in the expired alveolar gas in patients with liver cirrhosis. Clin. Chim. Acta 85: 279, 1978.

12) Favier A \& Caillat D: Determination of urinary $\alpha$ keto- $\gamma$-methylthiobutyric acid in hypermethioninemia by use of gas chromatography and flame photometry. Clin. Chim. Acta 79: 419, 1977.

13) Kaji H, Saito N, Murao M, et al: Gas chromatographic and gas chromatographic-mass spectrometric studies on $\alpha$-keto- $\gamma$-methylthiobutyric acid in urine following ingestion of optical isomers of methionine. J. Chromatogr. 221: 145, 1980.

14) Brown RF, Godfrey KR, Knell A: Compartmental modelling based on methionine tolerance test data: a case study. Med. Biol. Eng. Comput. 17: 223, 1979.

15) Steele RD \& Benevenga NJ: Identification of 3methylthiopropionic acid as an intermediate in mammalian methionine metabolism in vitro. J. Biol. Chem. 253: 7844, 1978.

16) Steele RD \& Benevenga NJ: The metabolism of 3methylthiopropionate in rat liver homogenates. J. Biol. Chem. 254: 8885, 1979.

17) Dixon JL \& Benevenga NJ: The decarboxylation of $\alpha$-keto- $\gamma$-methiolbutyrate in rat liver mitochondria. Biochem. Biophys. Res. Commun. 97: 939, 1980.

18) Challenger F \& Walshe JM: (1955a) Methyl mercaptan in relation to fetor hepaticus. Biochem. J. 59: 372, 1955.

19) Challenger F \& Walshe JM: Foetor hepaticus. Lancet 1: $1239,1955$.

20) Challenger F: Aspects of the Organic Chemistry of Sulfur. (Cook JW, Stacey PM, eds), Butterworths Scientific Publications, London, 1959.

21) Canellakis ES \& Tarver H: Studies on protein synthesis in vitro. IV. Concerning the apparent uptake of methionine by particulate preparation from liver. Arch. Biochem. Biophys. 42: 387, 1953.

22) Tarbell DS: Organic Sulfur Compounds, volume 1. The Mechanism of oxidation of thiols to disulfides. (Kharasch N, ed), Pergamon Press, New York, p 97$102,1961$. 